\title{
Assessment of a Simplified Correlation Between Wettability Measurement and Dispersion/ Coagulation Potency of Oxide Particles in Ferrous Alloy Melt
}

\begin{abstract}
KEIJI NAKAJIMA, WANGZHONG MU (D), and PÄR G. JÖNSSON
This article seeks to demonstrate a direct and simplified correlation between the measurement of the wettability and the agglomeration potency of the inclusion particles in liquid ferrous alloy. The established methodology has been validated by the agreement between the calculated coagulation coefficient of $\mathrm{Al}_{2} \mathrm{O}_{3}$ particles and the experimental data in the open literature. Subsequently, the coagulation coefficient of $\mathrm{Al}_{2} \mathrm{O}_{3}, \mathrm{MgO}$, and $\mathrm{Ti}_{2} \mathrm{O}_{3}$ particles in ferrous alloy melts was evaluated quantitatively by the proposed method using the actual experimental data of contact angle and surface tension. Meanwhile, the effect of the matrix composition has been investigated by comparing the Hamaker constant and coagulation coefficient between $\mathrm{Ti}_{2} \mathrm{O}_{3} /$ pure iron and $\mathrm{Ti}_{2} \mathrm{O}_{3} /$ low-carbon steel systems. It is noted that the change of coagulation coefficient associated with the contact angle is caused by the formation of a new phase at the oxide/metal interface at the high temperature. The present work aims to provide a deep understanding of the connection between inclusion motion behavior in the liquid alloy and the high temperature interfacial phenomenon.
\end{abstract}

https://doi.org/10.1007/s11663-019-01624-x

(C) The Author(s) 2019

\section{INTRODUCTION}

PhysicochemicAl aspects focusing on the motion, agglomeration, and detachment behaviors of particles in the liquid or at liquid-gas interface are of great importance in the different fields including metallurgical engineering. The particles can refer to metal droplet, aerosol, colloid particle, nonmetallic inclusion particles in the different engineering fields. ${ }^{[1]}$ Specifically, the agglomeration of inclusion particles in the liquid metal is vital to control the cleanliness of steels. ${ }^{[2,3]}$ In addition, their agglomeration behavior relates to the inclusion size, which is an important factor for inclusion roles as a nucleation site to induce intragranular acicular ferrite nucleation. ${ }^{[4]}$ Moreover, there is a concept, inclusion engineering, that deals with the control of the amount, morphology, size distribution, and composition of nonmetallic inclusions formed in the liquid steel during refining and solidification. ${ }^{[10]}$ To better understand the mechanism of inclusion agglomeration

KEIJI NAKAJIMA, WANGZHONG MU, and PÄR G. JÖNSSON are with the KTH Royal Institute of Technology, Department of Materials Science and Engineering, Brinellvägen 23, 10044 Stockholm, Sweden. Contact e-mail: wmu@kth.se

Manuscript submitted December 27, 2019.

Article published online June 19, 2019. behavior, the experimental studies using both in-situ $^{[11-15]}$ and ex-situ ${ }^{[16-19]}$ methodologies have been performed. However, the current in-situ characterization research by high-temperature confocal laser scanning microscope (HT-CLSM) limits the inclusion behavior on the liquid steel surface or named steel-gas interface, which is a much different mechanism with the case of inclusion agglomeration at the bulk of the liquid steel. For the latter case, to the authors' best knowledge, there is not an available way to characterize this research topic directly. Using high-energy X-ray or neutron may have the chance; however, due to the low density of inclusion existed in the liquid steel, the resolution of the current X-ray, as well as that of the neutron, is not high enough. Alternatively, the Hamaker constant and coagulation coefficient can be used to support the experimental findings in References 13 through 19.

Besides the experimental work, various simulation studies of the inclusion agglomeration behavior in the liquid steel have been carried out by using the turbulent collision rate, which is a function of the coagulation coefficient. ${ }^{[20-23]}$ In some studies, the inclusion has been assumed to be a single phase and the coagulation coefficient was set to a constant value of one for the sake of convenience. As a result, it was not possible to discuss quantitatively on the size distribution of different inclusion kinds. ${ }^{[22,23]}$ 
Therefore, the proposed method aims to demonstrate a simplified but direct correlation between the fundamental study of the wettability measurement and the practical phenomenon of inclusion agglomeration in the liquid steel. First of all, the current methodology proposed a correlation between the contact angle and the Hamaker constant according to Frenkel's method. ${ }^{[24]}$ Subsequently the relationship between the Hamaker constant and the coagulation coefficient based on the turbulent coagulation model is established. Thereafter, this integration method is verified by the experimental data of the $\mathrm{Al}_{2} \mathrm{O}_{3}$ particles in liquid iron. Finally, the difference between the coagulation coefficient and the Hamaker constant among $\mathrm{Al}_{2} \mathrm{O}_{3}, \mathrm{MgO}$, and $\mathrm{Ti}_{2} \mathrm{O}_{3}$ particles in the liquid iron/low-carbon steel is compared. The success of the applicability of the proposed method will let the industrial community assess the inclusion elimination efficiency rapidly according to the experimental database of the physical property measurement from the academic community. We challenge it here.

\section{METHODOLOGY}

\section{A. Calculation of Hamaker Constant}

The flowchart of the calculation proposed in this work is presented in Figure 1. Prior to the calculation of the coagulation coefficient, it is important to introduce the calculation method of Hamaker's constant using the physical measurement data. According to the history of this parameter, Hamaker ${ }^{[25]}$ was the pioneer who reported that the adhesion force, London-v.d. Waals interaction (vdW), exists between two small particles. The vdW of two spherical particles can be calculated as a function of the diameters and the distance separating them. Moreover, it is reported that the vdW force could split into a geometrical part associated with a parameter called the "Hamaker constant." The basic equation to calculate this factor is provided in Reference 25 . Subsequently, a description of the vdW interaction with

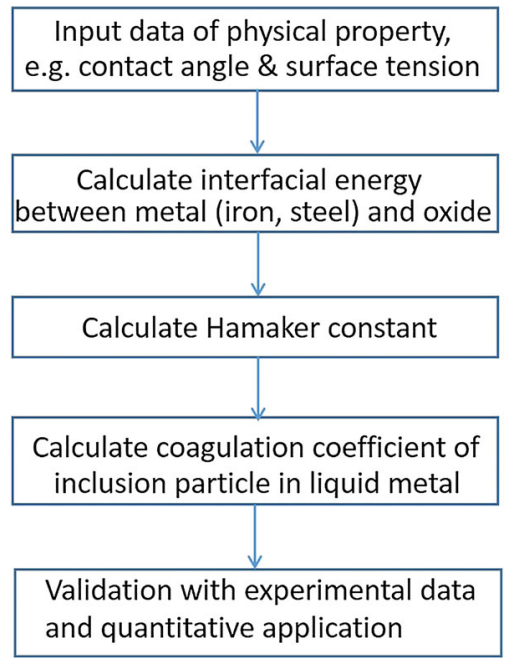

Fig. 1-Flowchart of the present calculation process. the consideration of the dielectric property of the intervening medium was introduced by Lifshitz. ${ }^{[26]}$ Visser $^{[27]}$ reviewed the existing approximate equations for the calculations of the Hamaker constant from experiments, where the methods reported by Frenkel ${ }^{[24]}$ and Fowkes ${ }^{[28]}$ based on physical property measurements were introduced. Actually, there are several mechanisms of collision-coagulation other than $\mathrm{vdW}$ force that can also contribute to the particle agglomeration. For instance, liquid bridge force, cavity bridge force, and capillary force are also the reason. However, the focus of this work is $\mathrm{vdW}$ force, which only relates to the Hamaker constant and coagulation coefficient. The applicability of the Hamaker constant has been reported in the colloid chemistry. ${ }^{[27]}$ Meanwhile, Taniguchi et al. ${ }^{[29]}$ utilized this concept in the physical model, which simulates the particle motion behavior in the steelmaking. It is noted that these Hamaker constant values obtained from the surface tension measurement agreed well with other methods at room temperature, such as graphite, polystyrene, polymers, $\mathrm{SiO}_{2}$, and $\mathrm{TiO}_{2}$ in water solution. ${ }^{[20,27,29]}$ Regarding the Hamaker constant application at high temperature, Lin and Shimme ${ }^{[30]}$ have tried to estimate the Hamaker constant for $\mathrm{Al}_{2} \mathrm{O}_{3}$ in an iron melt, based on Fowkes's method. ${ }^{\text {[28] }}$ However, it might not be a perfect estimation since this value was used for the adhesion between $\mathrm{Al}_{2} \mathrm{O}_{3}$ and liquid iron at $1600{ }^{\circ} \mathrm{C}$. Alternatively, the selected Hamaker constant of $\mathrm{Al}_{2} \mathrm{O}_{3}$ is at room temperature.

From the viewpoint of its applicability to particle dispersion/coagulation phenomena and the simplicity using physical property at high temperature, the original equation by Frenkel ${ }^{[24]}$ was adopted. Subsequently, the Hamaker constant is viewed as a system-specific physical constant for a system in which the intervening media is iron/steel melt (M) and the two adjacent particles are oxide inclusions (I). However, it depends apparently on the temperature and time because the composition of the intervening medium and the particle changes slightly with the temperature as well as with the holding time.

According to Frenkel's method, ${ }^{[24]}$ the interfacial adhesion energy between two particles with a plate shape is expressed as $-2 \gamma_{\text {IM }}$ per unit area. On the other hand, the van der Waals interaction free energy between two particles with a plate shape is $-A_{\mathrm{IMI}} / 12 \pi a^{2}$ per unit area. Thus, using the van der Waals adsorption approximation, the following equations can be obtained as Eqs. [1] and [2], and the details can be seen in References 13 and 14

$$
A_{\mathrm{IMI}}=24 \pi a^{2} \gamma_{\mathrm{IM}}
$$

$$
\gamma_{\mathrm{IM}}=\gamma_{\mathrm{I}}-\gamma_{\mathrm{M}} \cos \theta_{\mathrm{IM}}
$$

where $A_{\text {IMI }}$ is the Hamaker constant $(\mathrm{J})$; a is the ionic radius, which is $2.8 \times 10^{-10}$ for the oxides and $3.4 \times 10^{-10}$ for the nitrides $(\mathrm{m}) ; \gamma_{\mathrm{I}}$ is the surface energy of oxide $\left(\mathrm{J} / \mathrm{m}^{2}\right) ; \gamma_{M}$ is the surface tension of iron/steel melt $\left(\mathrm{N} / \mathrm{m}\right.$, equivalent to $\left.\mathrm{J} / \mathrm{m}^{2}\right)$; and $\gamma_{\mathrm{IM}}$ and $\theta_{\text {IM }}$ are the interfacial free energy $\left(\mathrm{J} / \mathrm{m}^{2}\right)$ as well as the 
contact angle (degrees) between iron/steel melt and the oxide substrate. Thus, the Hamaker constant at high temperature, $A_{\text {IMI }}$, can be obtained from the contact angle data $\left(\theta_{\text {IM }}\right) \cdot \gamma_{\text {IM }}$ is the interfacial free energy between iron/steel melt and oxide.

\section{B. Relationship Between Hamaker Constant and Coagulation Coefficient}

It is speculated that the viscous drag force and the van der Waals force act on the particles in the liquid metal. See the schematic illustration in Figure 2. At the time of the collide-contact between particles, the viscous drag force exerts through the thinning of the film layer of an iron liquid atom between the particles. The viscous drag force will inhibit the collision because it becomes much stronger as the particles approach each other. Meanwhile, the van der Waals force promotes the collision as an attractive force between the particles.

Based on this consideration, Higashitani et al. ${ }^{[31,32]}$ proposed the relationship between the Hamaker constant and the coagulation coefficient, $\alpha_{t}$, for the turbulent collision. This was done based on the experiment results obtained from room temperature of polystyrene latex (PSL) particles with a diameter of $0.85 \mu \mathrm{m}$ and polyvinyltoluene latex (PVTL) particles with a diameter of $2.17 \mu \mathrm{m}$ in $\mathrm{KCl}$ aqueous solution. This consideration is based on the turbulent collision rate of Suffman and Turner. ${ }^{[33]}$ Furthermore, the collision coalescence among inclusion particles over a diameter of $1 \mu \mathrm{m}$ in the iron/steel melt happens mainly due to the turbulent collisions. ${ }^{[34]}$ The turbulent collision rate $\beta^{\mathrm{T}} i j\left(\mathrm{~m}^{3} / \mathrm{s}\right)$ and coagulation coefficient $\left(\alpha_{t}\right)$ are defined as follows:

$$
\begin{gathered}
\beta_{i j}^{\mathrm{T}}=1.3 \alpha_{\mathrm{t}} \sqrt{\pi \rho_{\mathrm{f}} \varepsilon / \mu}\left(r_{i}+r_{j}\right)^{3} \\
\alpha_{\mathrm{t}}=0.727\left[\frac{\mu r_{i}^{3}\left(\rho_{\mathrm{f}} \varepsilon / \mu\right)^{1 / 2}}{A_{\mathrm{IMI}}}\right]^{-0.242}
\end{gathered}
$$

where $r_{i}$ and $r_{j}$ are radii of the inclusion particles $(\mathrm{m})$, $\rho_{f}$ is the density of iron/steel melt $\left(\mathrm{kg} / \mathrm{m}^{3}\right), \varepsilon$ is the turbulent energy dissipation rate $\left(0.01 \mathrm{~m}^{2} / \mathrm{s}^{3}\right)$, and $\mu$ is the viscosity of iron/steel melt $\left(6.92 \times 10^{-3} \mathrm{~Pa} \mathrm{~s}\right)$.

\section{Summary of Contact Angle and Surface Tension Measurement in Previous Work}

The experimental data of contact angle and surface tension used for Hamaker constant calculation are obtained from the sessile drop measurement reported in previous studies. ${ }^{[35-37]}$ The schematic illustration of the experimental apparatus as well as the contact angle measurement by sessile drop are shown in Figures 3(a) and (b), and the details of the experimental procedure can be seen in References 38 and 39. Meanwhile, the digital photos taken during the sessile drop measurement were used for the surface tension measurement. The classic method named "Profile Fitting Method (PFM)" summarized by Padday ${ }^{[40]}$ associated with the Bashforth and Adams tables ${ }^{[41]}$ was used for the calculation. The schematic figure showing the surface tension measurement of a droplet is presented as Figure 3(c). The oxygen partial pressure for the inlet and outlet Ar gas was monitored by the oxygen sensor. Details can be seen in Reference 35 .

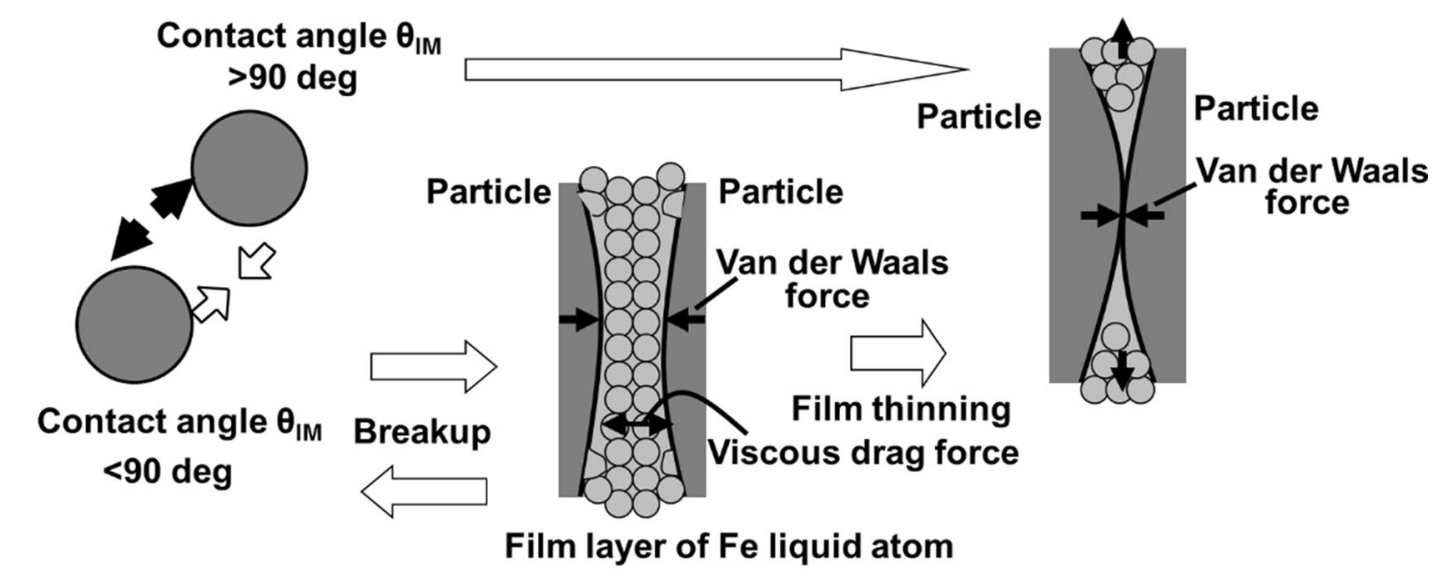

i) Collision of two particles

ii) Unstable coagulation

ii) Complete coagulation

Fig. 2-Influence of wettability on the particle dispersion/coagulation process. 

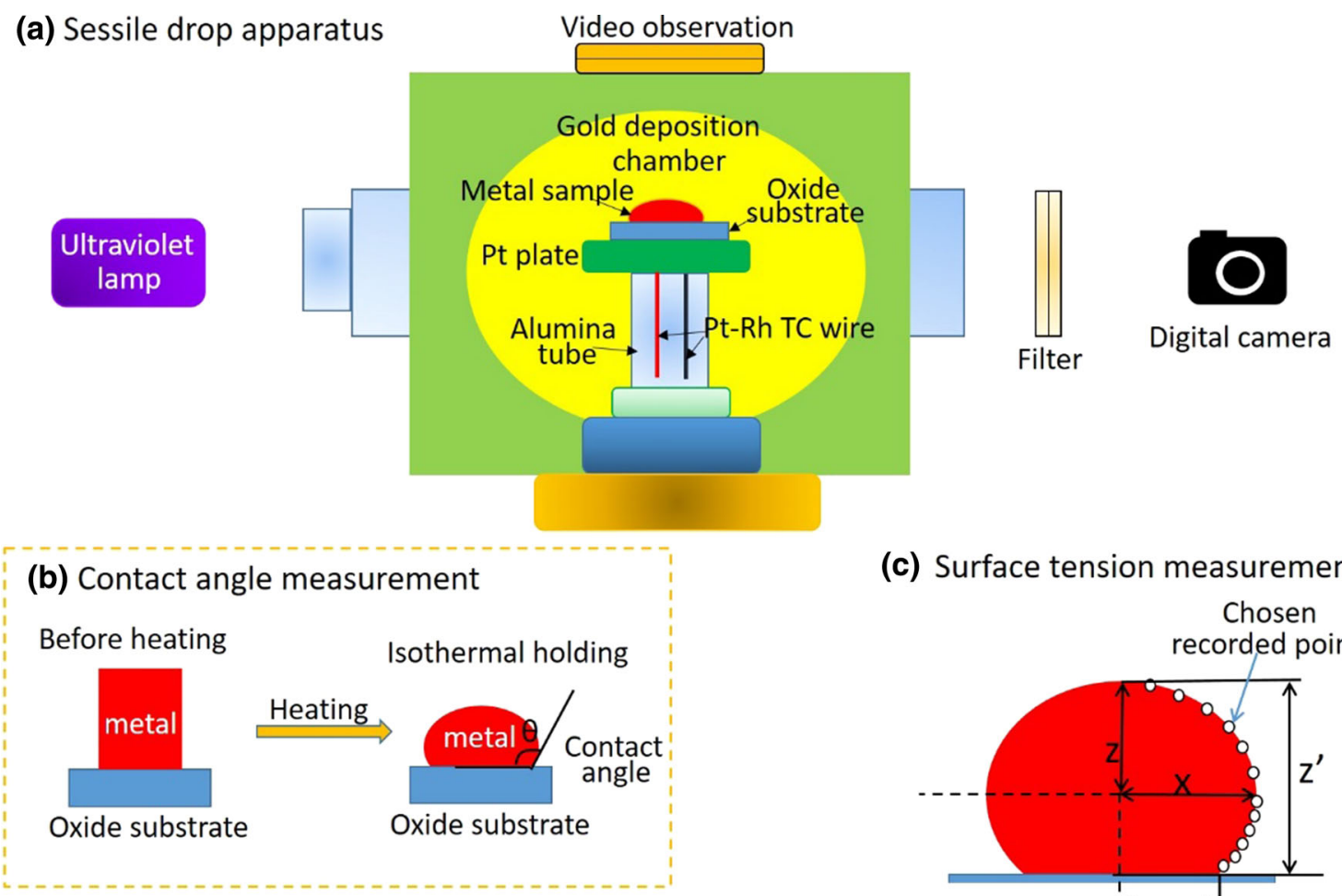

(c) Surface tension measurement

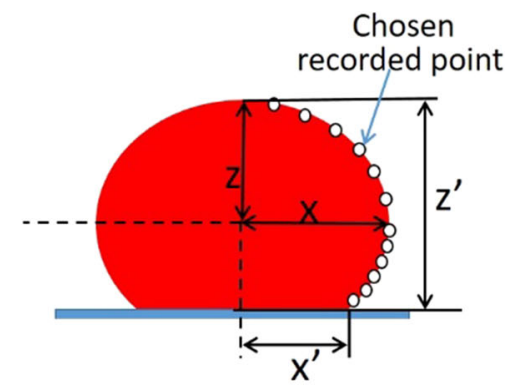

Fig. 3-Schematic illustration of $(a)$ sessile drop apparatus, $(b)$ contact angle measurement, and $(c)$ surface tension measurement. The figures are adapted from Refs. [35], [38], and [39]

\section{RESULTS AND DISCUSSION}

\section{A. Input Data Selection}

The physical properties, $\theta_{\mathrm{IM}}, \gamma_{\mathrm{M}}, \gamma_{\mathrm{I}}$, for a specific oxide/metal system are necessary for the calculation of the Hamaker constant. Therefore, the data obtained from the sessile drop measurement are very suitable because it can simultaneously obtain the contact angle and surface tension. Moreover, the dissolved $[\mathrm{O}]$ content in the matrix closed to the oxide/metal interface associates with the physical property changes. The change of $[\mathrm{O}]$ is caused by oxygen partial pressure, $\mathrm{Po}_{2}$, in the gas atmosphere. The $\mathrm{Po}_{2}$ value at $1815 \mathrm{~K}$ reported in Reference 35 is estimated to range $10^{-9}$ to $10^{-7} \mathrm{~atm}$ based on the assumption of $\mathrm{H}_{2} / \mathrm{H}_{2} \mathrm{O}$ equilibrium using the inlet oxygen sensor measurement data. However, they assume the ratio of $\mathrm{P}_{\mathrm{H}_{2} \mathrm{O}} / \mathrm{P}_{\mathrm{H}_{2}}$ is constant in the range from $923 \mathrm{~K}$ to $1815 \mathrm{~K}$. In addition, the working temperature of the inlet oxygen sensor is assumed to be $923 \mathrm{~K}$. These assumptions can lead to an overestimation for the actual value of $\mathrm{Po}_{2}$ at $1815 \mathrm{~K}$. Therefore, the authors reestimated the $\mathrm{Po}_{2}$ to be from $10^{-11}$ to $10^{-9}$ atm considering the variation of the inlet Ar temperature. Actually the product layer $\left(\mathrm{FeAl}_{2} \mathrm{O}_{4}\right)$ at this $\mathrm{Po}_{2}$ level is also recognized in the case of the similar level of $\mathrm{PO}_{2}$ by Ogino et al. ${ }^{[36]}$ Thus, this value is used in this work. Here, we used the experimental data obtained from the previous sessile drop studies by Xuan et al. ${ }^{[35]}$ and Ogino et al. ${ }^{[36,37]}$ for $\gamma_{\mathrm{M}}$ and $\theta_{\mathrm{IM}}$. The details of these data will show in the following section. In addition, we use the reported data of $\gamma_{I}$ obtained from the previous works by $\mathrm{Nakajima}^{[42]}$ and Hara et al., ${ }^{[43]}$ where $0.75 \mathrm{~J} / \mathrm{m}^{2}$ for $\mathrm{Al}_{2} \mathrm{O}_{3}, 0.71 \mathrm{~J} / \mathrm{m}^{2}$ for $\mathrm{MgO}$, and $0.574 \mathrm{~J} / \mathrm{m}^{2}$ for $\mathrm{Ti}_{2} \mathrm{O}_{3}$.

\section{B. Effect of Oxide Composition on the Relationship Between Contact Angle, Hamaker Constant, and Coagulation Coefficient}

\section{1. $\mathrm{Al}_{2} \mathrm{O}_{3}$ /Pure Fe}

Figures 4(a) and (b) show the change of contact angle and the surface tension between $\mathrm{Al}_{2} \mathrm{O}_{3}$ and pure iron with the increasing holding time. It is seen that the contact angle and the surface tension between pure iron and oxide substrate decrease with the increasing holding time at the high oxygen partial potential $\left(\mathrm{Po}_{2}\right)$ of $10^{-9}$ to $10^{-11} \mathrm{~atm}$. This is actually due to the composition of the oxide interface changes and the $[\mathrm{O}]$ content increases in the iron/steel melt. However, the contact angle and the surface tension between $\mathrm{Al}_{2} \mathrm{O}_{3}$ and pure iron keep almost constant with $10^{-19} \mathrm{~atm}$ of $\mathrm{Po}_{2}$. The evidence of the interface validation has been identified by scanning electron microscopy with energy-dispersive X-ray spectroscopy (SEM-EDS) ${ }^{[35,36]}$ It is seen that $\mathrm{FeAl}_{2} \mathrm{O}_{4}$ is the stable phase at the $\mathrm{Al}_{2} \mathrm{O}_{3}$ /pure iron interface with $10^{-9}$ to $10^{-11} \mathrm{~atm}$ of $\mathrm{Po}_{2}$, and the thickness of the formed $\mathrm{FeAl}_{2} \mathrm{O}_{4}$ is approximately $4 \mu \mathrm{m} \cdot{ }^{[35]}$ However, the interface remains as $\mathrm{Al}_{2} \mathrm{O}_{3}$ at $10^{-19}$ atm of $\mathrm{Po}_{2}$. In addition, an obvious decrease of the surface tension stops at 90 seconds, as reported by Xuan et al. ${ }^{[35]}$ and at 300 seconds for $\mathrm{Po}_{2}$ of $8.5 \times 10^{-9} \mathrm{~atm}$, as reported by Ognio et al. ${ }^{[36]}$ Based on the these statements, the initial points 

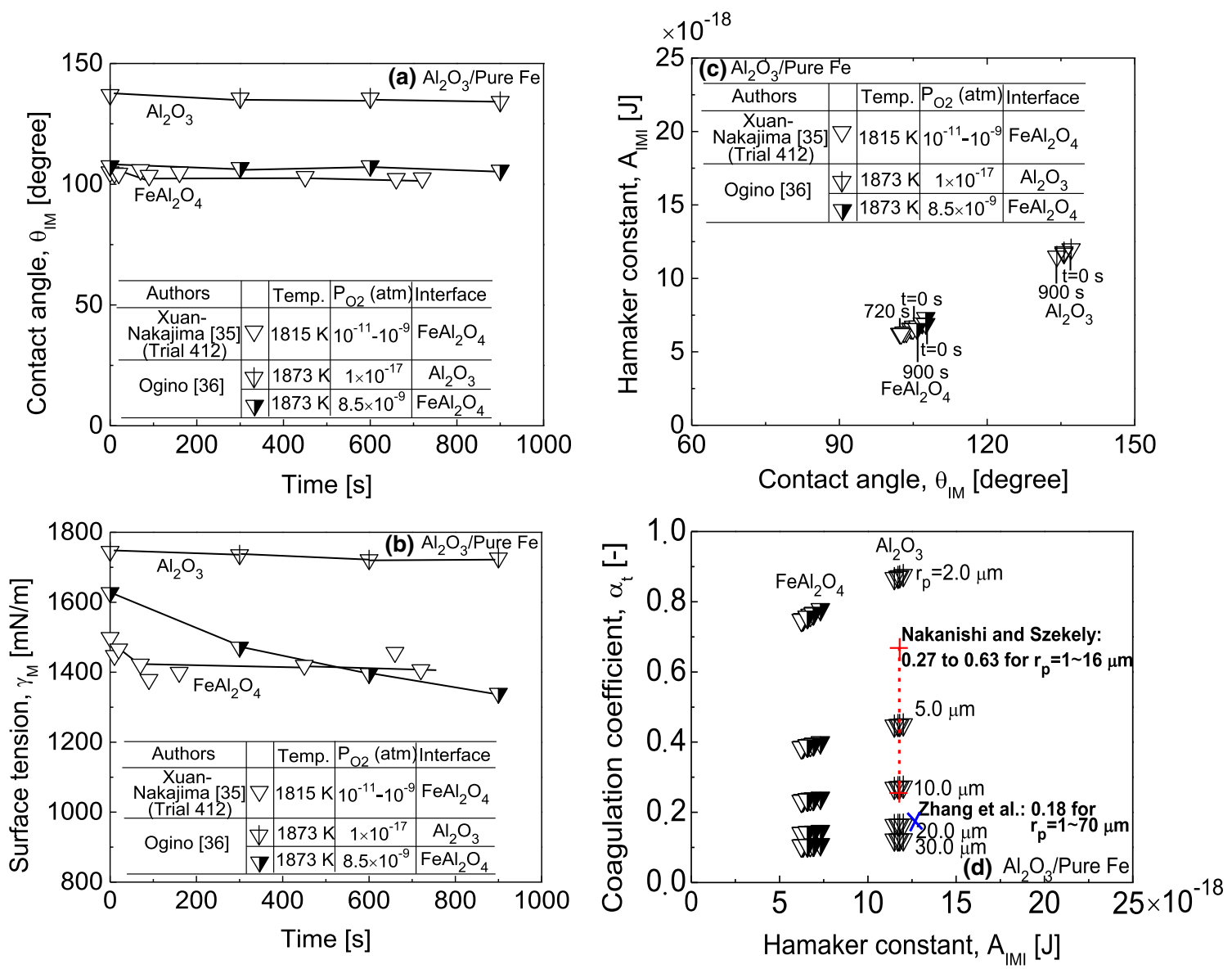

Fig. 4 Change of $(a)$ contact angle and $(b)$ surface tension with time, $(c)$ the relationship between contact angle and Hamaker constant, and $(d)$ the relationship between Hamaker constant and coagulation coefficient in the $\mathrm{Al}_{2} \mathrm{O}_{3} / \mathrm{Pure}$ Fe system.

in Figures 4(a) and (b) are recognized as the actual value of the contact angle and the surface tension. Comparing the reported initial experimental data in References 35 and 36 , the composition change of the interface leads to a decrease of the initial contact angle from 136 to 104 deg. Subsequently it leads to a decrease of the Hamaker constant from 11.8 to $6.7 \times 10^{-18} \mathrm{~J}$ and, finally, to a 13 pct decrease of the coagulation coefficient. This can be seen in Figures 4(c) and (d).

The proposed simplification method linking the wettability measurement and the coagulation coefficient has been validated by the previous experimental data. ${ }^{[4,45]}$ Specifically, Nakanishi and Szekely ${ }^{[44]}$ have reported that the coagulation coefficient, $\alpha_{t}$, equals a value between 0.27 and 0.63 for $\mathrm{Al}_{2} \mathrm{O}_{3}$ inclusion with a radius of 1 to $16 \mu \mathrm{m}$. This conclusion was based on a comparison of the calculation and the experimental values of the turbulent coagulation rates under $\mathrm{Al}$ deoxidation in the ASEA-SKF furnace. This can be seen in Figure 4(d). In addition, Zhang et al. ${ }^{[45]}$ have estimated that the coagulation coefficient, $\alpha_{t}$, equals 0.18 for an $\mathrm{Al}_{2} \mathrm{O}_{3}$ inclusion with a radius of 1 to $70 \mu \mathrm{m}$, where the main inclusion size is about $25 \mu \mathrm{m}$, in a continuous casting tundish. These values agree quite acceptably with the predicted values by the present method, which are 0.19 to 1.0 and 0.14 , respectively. The agreement from the validation provides a reliable path that the current method can be applicable in predicting comprehensive kinds of inclusion agglomeration in the melt.

\section{2. $\mathrm{MgO} /$ Pure $\mathrm{Fe}$}

For the case of $\mathrm{MgO} /$ pure iron system, it is seen that experimental data of contact angle and surface tension decreases with the increasing holding time for the case of relatively high $\mathrm{Po}_{2}$ of $10^{-11}$ to $10^{-9}$ atm. For the case of low $\mathrm{Po}_{2}$ of $10^{-17} \mathrm{~atm}$, the drop of contact angle can be found; however, the surface tension almost keeps as a constant value. See Figures 5(a) and (b). According to $\mathrm{Po}_{2}$ in different measurements, the composition of the $\mathrm{MgO} /$ pure iron interface is characterized as $\mathrm{MgO}$ at the $\mathrm{Po}_{2}$ of $10^{-17} \mathrm{~atm},{ }^{[37]}$ and $\mathrm{MgO} \cdot \mathrm{FeO}$ at the $\mathrm{Po}_{2}$ of $10^{-11}$ to $10^{-9}$ atm by SEM-EDS. ${ }^{[35]}$ It is reported that $\mathrm{FeO}$ can be formed at the interface between $\mathrm{MgO}$ and liquid iron when the $\mathrm{Po}_{2}$ is relatively high; subsequently, $\mathrm{FeO}$ can immediately mix with $\mathrm{MgO}$ to form $\mathrm{MgO} \cdot \mathrm{FeO}$ solid solution (s.s.). ${ }^{[46]}$ After 400 seconds, both the contact angle and the surface tension reported in Reference 36 almost remain as a constant value because the reaction layer formation almost reached an equilibrium state. In addition, the reason for the slight drop of the contact angle at the $\mathrm{PO}_{2}$ of $10^{-17}$ atm is not clear since the interface remains as $\mathrm{MgO}$ and the surface tension keeps 

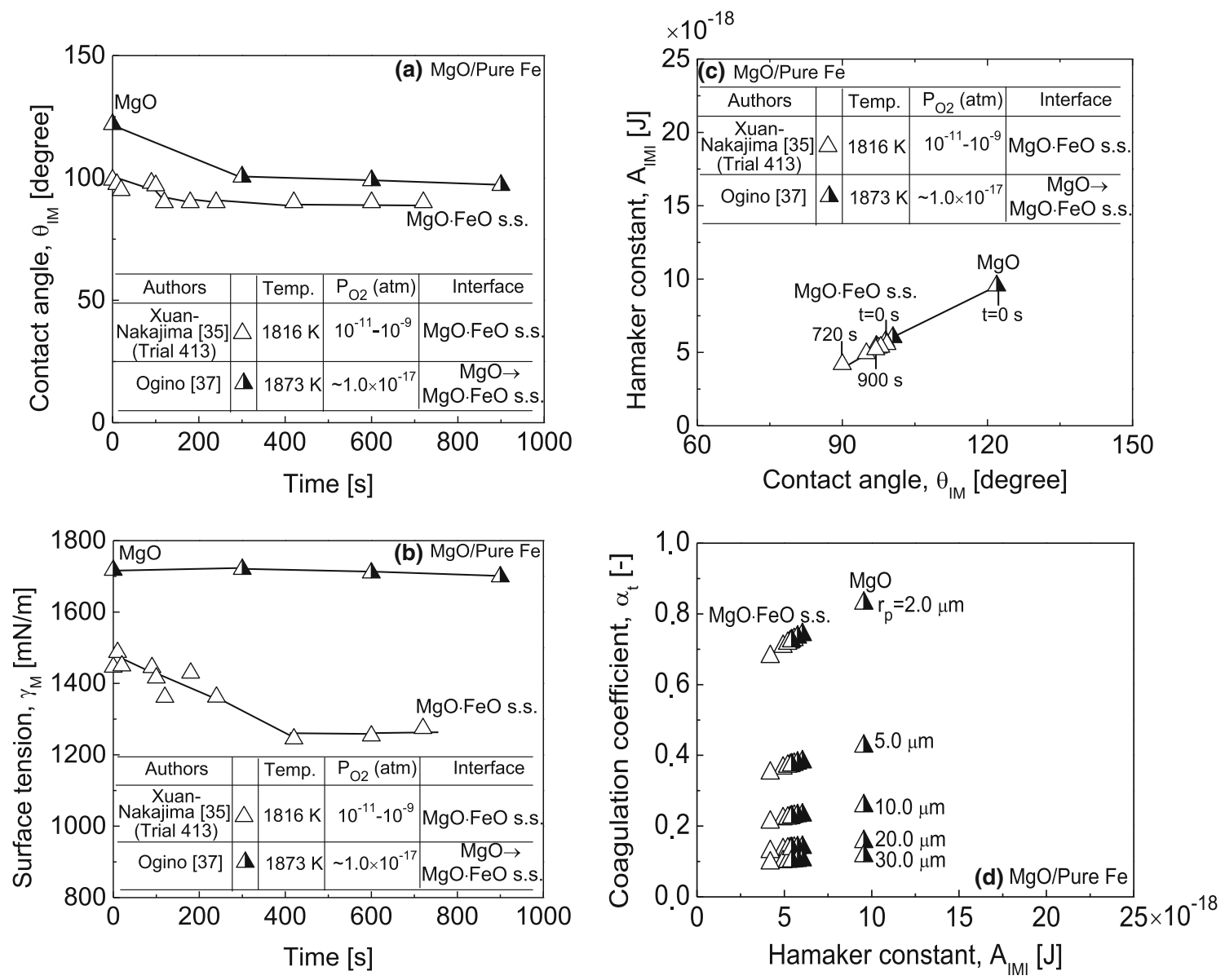

Fig. 5-Change of $(a)$ contact angle and $(b)$ surface tension with time, $(c)$ the relationship between contact angle and Hamaker constant, and $(d)$ the relationship between Hamaker constant and coagulation coefficient in the $\mathrm{MgO} / \mathrm{Pure}$ Fe system.

almost stable. However, it is believed to be due to the increase of the dissolve oxygen content in the pure iron closed to the interface.

Consequently, the difference between the initial contact angles at $\mathrm{Po}_{2}$ values of $10^{-11}$ to $10^{-9}$ atm and $10^{-17}$ atm is due to the phase change at the $\mathrm{MgO} /$ pure iron interface. This leads to a decrease of actual contact angle from 122 to $90 \mathrm{deg}$, the Hamaker constant from 9.6 to $4.2 \times 10^{-18} \mathrm{~J}$, and finally a 18 pet decrease of coagulation coefficient. See the details in Figures 5(c) and (d).

\section{Effect of Matrix Composition on the Relationship Between Contact Angle, Hamaker Constant, and Coagulation Coefficient}

\section{1. $\mathrm{Ti}_{2} \mathrm{O}_{3}$ Pure $\mathrm{Fe}$}

Unlike the cases of $\mathrm{Al}_{2} \mathrm{O}_{3} /$ pure iron and $\mathrm{MgO} /$ pure iron, the contact angle and surface tension of $\mathrm{Ti}_{2} \mathrm{O}_{3} /$ pure iron almost keep stable with the increasing holding time. This tendency can be seen in Figures 6(a) and (b). A very slight drop of the contact angle from 128 to $119 \mathrm{deg}$ after holding 726 seconds can be found. This is most probably due to the slightly increase of the dissolved [O] content in the matrix adjacent to the interface. In addition, two datasets of the surface tension keep almost $1.55 \mathrm{~N} / \mathrm{m}$ and $1.65 \mathrm{~N} / \mathrm{m}$. The difference has not been directly reported in References 35, but it is most probably due to the different $\mathrm{Po}_{2}$ values during the measurement. It is not supervising to note that the slight drop of contact angle leads to a small decrease of the Hamaker constant from 9.3 to $8.3 \times 10^{-18} \mathrm{~J}$ and, finally, contributes to an only 3 pct decrease of coagulation coefficient. The details can be seen in Figures 6(c) and (d). In addition, the interface is observed to change from $\mathrm{Ti}_{2} \mathrm{O}_{3}$ to $\mathrm{TiO}_{x}(x=1.0$ and 1.2) for the two cases. The actual reason is still not clear yet; however, the oxygen reduction is believed to be due to the stable composition of the solid solution, $\mathrm{TiO}_{x}$, in equilibrium with pure iron. The authors would investigate this phenomenon carefully in future work.

The Hamaker constant and the coagulation coefficient for each oxide particle in pure iron melt is summarized here. $\mathrm{Al}_{2} \mathrm{O}_{3}$ has the strongest coagulation potency vs that of other oxides. $\mathrm{Ti}_{2} \mathrm{O}_{3}$ and $\mathrm{MgO}$ are found to have a similar coagulation tendency, which is lower than $\mathrm{Al}_{2} \mathrm{O}_{3}$. The solid solution, $\mathrm{MgO} \cdot \mathrm{FeO}$, has the lowest one. It is important to note that the change of the Hamaker constant and coagulation coefficient directly depends on the chemical reaction at the interface between the metal and the oxide, which relates to the crystal structure revolution during the physical property measurement. 

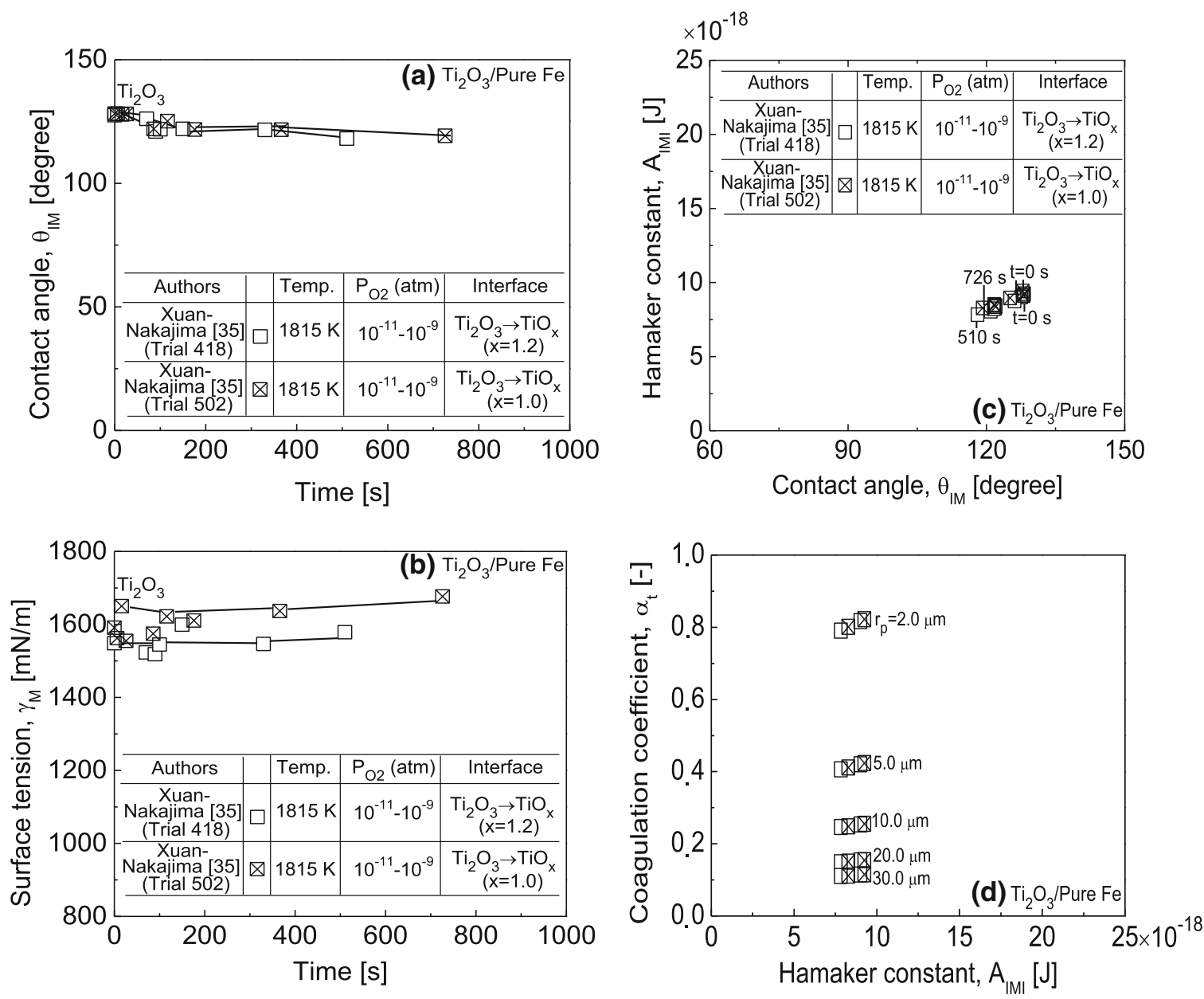

Fig. 6 - Change of $(a)$ contact angle and $(b)$ surface tension with time, $(c)$ the relationship between contact angle and Hamaker constant, and $(d)$ the relationship between Hamaker constant and coagulation coefficient in the $\mathrm{Ti}_{2} \mathrm{O}_{3} / \mathrm{Pure}$ Fe system.

\section{2. $\mathrm{Ti}_{2} \mathrm{O}_{3} /$ Steel}

Compared with the $\mathrm{Ti}_{2} \mathrm{O}_{3} /$ pure iron system, the relationship between the contact angle, Hamaker constant, and coagulation coefficient of $\mathrm{Ti}_{2} \mathrm{O}_{3}$ in low-carbon steel $\quad[\mathrm{Fe}-0.28 \mathrm{C}-1.43 \mathrm{Mn}-0.65 \mathrm{Si}-0.013 \mathrm{Al}-0.18 \mathrm{Cr}-0.13-$ Ni-0.084V-0.022Ti-0.042S, (mass pct)] is discussed here. Figures 7(a) and (b) show that the contact angle and the surface tension change with the increasing holding time. Although the contact angle almost remains as $128 \mathrm{deg}$ in the $\mathrm{Ti}_{2} \mathrm{O}_{3}$ /pure iron system, this parameter decreases significantly from 129 to 90 deg after holding from 12 to 720 seconds. A similar case occurs for the surface tension, which holds almost 1.55 and $1.65 \mathrm{~N} / \mathrm{m}$ of two datasets in the $\mathrm{Ti}_{2} \mathrm{O}_{3} /$ pure iron system. Subsequently, it drops from 1.65 to 1.1 obviously within 173 seconds in the $\mathrm{Ti}_{2} \mathrm{O}_{3} /$ steel system. The different behaviors of the physical property between the same kind of oxide particle but different matrix are believed to be due to the interfacial reaction between alloying element and $\mathrm{Ti}_{2} \mathrm{O}_{3}$ at the oxide/steel interface. This can lead to a composition change of the oxide interface from $\mathrm{Ti}_{2} \mathrm{O}_{3}$ to a mixture of $\left(\mathrm{Ti}_{1-x} \mathrm{Al}_{x}\right) \mathrm{O}_{y}(x=1.62$ at pet, $y=1.2)$.
The evidence is identified by SEM-EDS directly; meanwhile this product layer is believed to be a mixture of $\mathrm{Al}_{2} \mathrm{TiO}_{5}$ and $\mathrm{Ti}_{2} \mathrm{O}_{3}$ assisted by the thermodynamic calculation. $^{[35]}$ Besides the reported reason, it is well known that sulfur is one kind of strong surfactant that can reduce the surface tension significantly. A detailed quantitative study of the phase transition at the interface will be investigated by the authors in future work. Finally, Figures 7(c) and (d) show that the decrease of the contact angle and the surface tension during the isothermal holding leads to a decrease of Hamaker constant from 10.9 to $3.5 \times 10^{-18} \mathrm{~J}$ and, finally, to a 24 pct decrease of the coagulation coefficient.

\section{CONCLUSION}

This work provides a direct estimation methodology to determine the relationship between the wettability measurement and the coagulation coefficient of inclusion agglomeration in the liquid ferrous alloy. The following conclusions can be drawn here: 

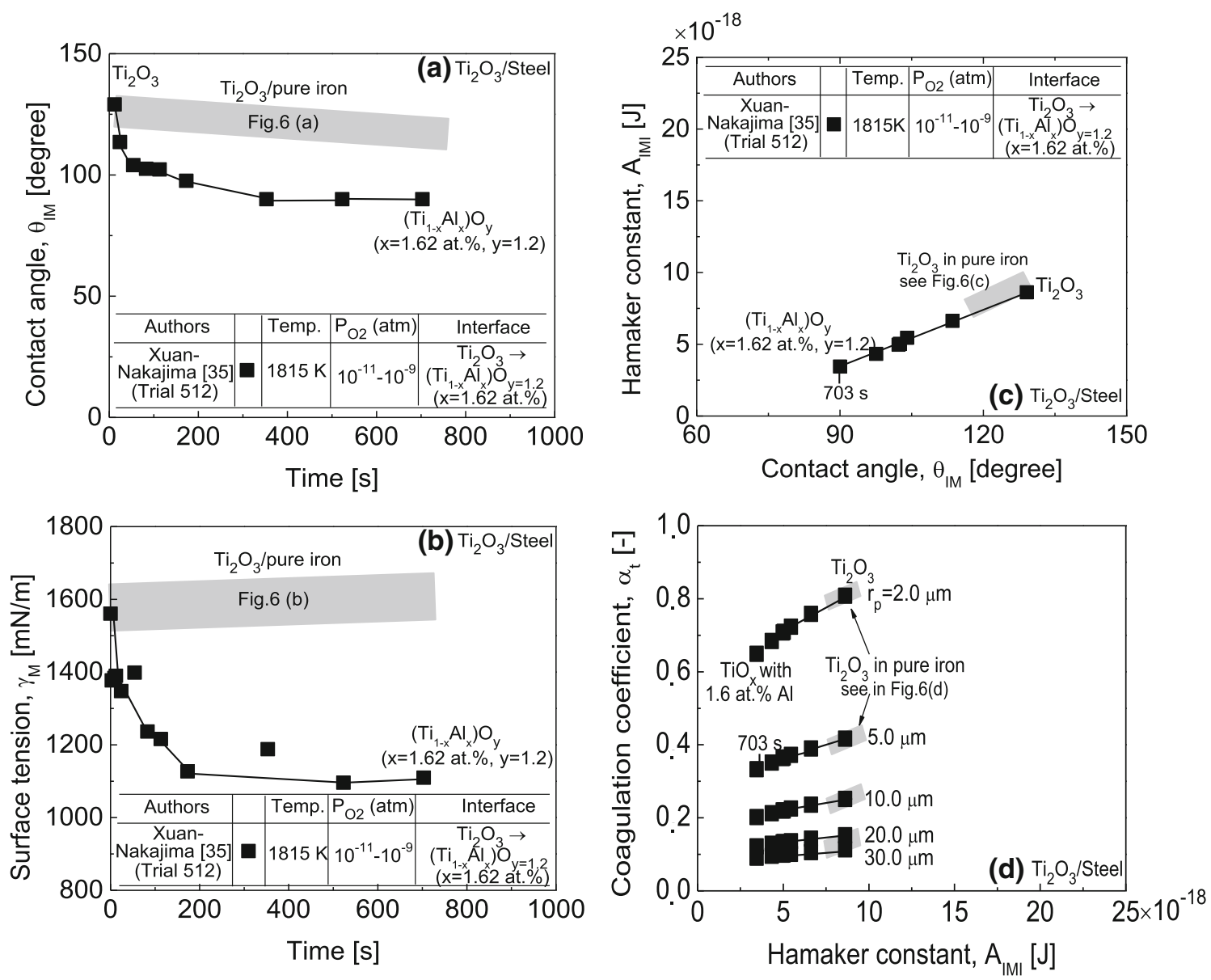

Fig. 7- Change of $(a)$ contact angle and $(b)$ surface tension with time, $(c)$ the relationship between contact angle and Hamaker constant, and $(d)$ the relationship between Hamaker constant and coagulation coefficient in the $\mathrm{Ti}_{2} \mathrm{O}_{3} / \mathrm{Steel}$ system.

(1) The present method calculating the coagulation coefficient is validated by the experimental data of the $\mathrm{Al}_{2} \mathrm{O}_{3}$ inclusion particle in a pure iron melt. Thus, the obtained results as well as the proposed methodology can be applied in the turbulent coagulation rate simulations.

(2) According to the difference of physical properties including contact angle and surface tension for each oxide/pure iron system, $\mathrm{Al}_{2} \mathrm{O}_{3}$ has the strongest coagulation potency vs that of the other oxides. $\mathrm{Ti}_{2} \mathrm{O}_{3}$ and $\mathrm{MgO}$ are found to have a similar coagulation tendency, which is lower than $\mathrm{Al}_{2} \mathrm{O}_{3}$. The solid solution, $\mathrm{MgO} \cdot \mathrm{FeO}$, has the lowest one.

(3) The Hamaker constant and the coagulation coefficient for $\mathrm{Ti}_{2} \mathrm{O}_{3}$ particle in low-carbon steel changes remarkably with time, which is a different behavior as that in the $\mathrm{Ti}_{2} \mathrm{O}_{3}$ /pure iron system. This phenomenon is due to the interface composition change from $\mathrm{TiO}_{x}(x=1.0 / 1.2)$ to a mixture of $\left(\mathrm{Ti}_{1-x} \mathrm{Al}_{x}\right) \mathrm{O}_{\mathrm{y}}(x=1.62$ at pct, $y=1.2)$.

(4) Physical property measurement of more comprehensive particle/metal systems considering various kinds of particles, e.g., nitrides, carbides, and sulfide, as well as high-alloy steel grades, e.g., high $\mathrm{Mn}$ steels and stainless steels can provide a more robust prediction of the inclusion agglomeration behavior in the actual steel manufacturing process.

\section{ACKNOWLEDGEMENTS}

W.M. would like to acknowledge financial support from The Swedish Foundation for International Cooperation in Research and Higher Education (STINT) (Grant No.: PT 2017-7330) and Jernkontoret (Swedish Steel Producers' Association).

\section{OPEN ACCESS}

This article is distributed under the terms of the Creative Commons Attribution 4.0 International License (http://creativecommons.org/licenses/by/4.0/), which permits unrestricted use, distribution, and reproduction in any medium, provided you give appropriate credit to the original author(s) and the source, provide a link to the Creative Commons license, and indicate if changes were made. 


\section{REFERENCES}

1. T.G. Anjali and M.G. Basavaraj: J. Colloid Interface Sci., 2016, vol. 478, pp. 63-71.

2. Y. Ren, L. Zhang, and S. Li: ISIJ Int., 2014, vol. 54, pp. 2772-9.

3. Y. Ren, L. Zhang, W. Yang, and H. Duan: Metall. Mater. Trans. $B, 2014$, vol. 45B, pp. 2057-71.

4. X. Zou, J. Sun, H. Matsuura, and C. Wang: Metall. Mater. Trans. $B, 2018$, vol. 49B, pp. 2168-73.

5. X. Zou, D. Zhao, J. Sun, C. Wang, and H. Matsuura: Metall. Mater. Trans. B, 2018, vol. 49B, pp. 481-9.

6. Q. Wang, X. Zou, H. Matsuura, and C. Wang: Metall. Mater. Trans. B, 2018, vol. 49B, pp. 18-22.

7. H. Kong, S. Shao, Y. Shen, Y. Zhou, Q. Yue, J. Zhang, and Z. Cai: High Temp. Mater. Proc., 2013, vol. 32, pp. 323-9.

8. H. Kong, Y. Shen, Y. Zhou, Q. Yue, L. Tong, and Z. Cai: Mater. Test., 2014, vol. 56, pp. 131-5.

9. W. Mu, N. Dogan, and K.S. Coley: JOM, 2018, vol. 70, pp. 1199 209.

10. O. Wijk: Proc. 7th Int. Conf. Refining Process (SCANINJECT VII), Luleå, Sweden, 1995, pp. 35-67.

11. S.K. Michelic and C. Bernhard: Scanning, 2017, Article ID 2326750, https://doi.org/10.1155/2017/2326750.

12. J. Wikström, K. Nakajima, H. Shibata, A. Tilliander, and P. Jönsson: Iron Steel, 2008, vol. 35, pp. 589-99.

13. W. Mu, N. Dogan, and K.S. Coley: Metall. Mater. Trans. B, 2017, vol. 48 B, pp. $2379-88$

14. W. Mu, N. Dogan, and K.S. Coley: Metall. Mater. Trans. B, 2017 , vol. 48B, pp. 2092-103.

15. W. Mu, N. Dogan, and K.S. Coley: J. Mater. Sci., 2018, vol. 53, pp. 13203-15.

16. H.E. Kellner, A.V. Karasev, O. Sundqvist, and P.G. Jönsson: ISIJ Int., 2018, vol. 58, pp. 292-8.

17. H.E. Kellner, A.V. Karasev, O. Sundqvist, and P.G. Jönsson: Steel Res. Int., Article ID 201700165, https://doi.org/10.1002/srin. 201700165.

18. C. Xuan, A.V. Karasev, and P.G. Jönsson: ISIJ Int., 2016, vol. 56, pp. $1204-9$

19. C. Xuan, A.V. Karasev, P.G. Jönsson, and K. Nakajima: Steel Res. Int., Article ID 1600090, https://doi.org/10.1002/srin.160009 0.

20. T. Nakaoka, K. Matsumoto, and S. Taniguchi: Prog. Comput. Fluid Dyn., 2008, vol. 8, pp. 270-5.

21. H. Ling, L. Zhang, and H. Li: Metall. Mater. Trans. B, 2016, vol. 47B, pp. 2991-3012.

22. H. Lei, K. Nakajima, and J.-C. He: ISIJ Int., 2010, vol. 50, pp. 1735-45.

23. H. Lei and J.-C. He: J. Mater. Sci. Technol., 2012, vol. 28, pp. $642-$ 6.
24. J. Frenkel: Kinetic Theory of Liquids, Dover, New York, 1995, Chapter VI, pp. 188-249.

25. H.C. Hamaker: Physica, 1937, vol. 4, pp. 1058-72.

26. E.M. Lifshitz: Sov. Phys. JETP, 1956, vol. 2, pp. 73-83.

27. J. Visser: Adv. Colloid Interface Sci., 1972, vol. 3, pp. 331-63.

28. F.M. Fowkes: in Surfaces and Interfaces: Chemical and Physical Characteristics, Burke, J.J., Reed, N.L., and Weiss, V., eds., Syracuse University Press, New York, 1967, pp. 197-202.

29. S. Taniguchi, A. Kikuchi, T. Ise, and N. Shoji: ISIJ Int., 1996, vol. 36, pp. S117-20.

30. W. Lin and K. Simme: Tetsu-to-Hagané, 1998, vol. 84, pp. 7-12.

31. H. Higashitani, K. Yamauchi, Y. Matsuno, and G. Hosokawa: $J$. Chem. Eng. Jpn., 1983, vol. 16, pp. 299-304.

32. T. Nakaoka, S. Taniguchi, K. Matsumoto, and S.T. Johansen: ISIJ Int., 2001, vol. 41, pp. 1103-11.

33. P.G. Saffman and J.S. Turner: J. Fluid Mech., 1956, vol. 1, pp. 1630.

34. S. Taniguchi and A. Kikuchi: Tetsu-to-Hagané, 1992, vol. 78, pp. 527-35.

35. C. Xuan, H. Shibata, S. Sukenaga, P. Jönsson, and K. Nakajima: ISIJ Int., 2015, vol. 55, pp. 1882-90.

36. K. Ogino, K. Nogi, and Y. Koshida: Tetsu-to-Hagané, 1973, vol. 59 , pp. $1380-7$.

37. K. Ogino, A. Adachi, and N. Nogi: Tetsu-to-Hagané, 1973, vol. 59, pp. 1237-44.

38. H. Shibata, Y. Watanabe, K. Nakajima, and S.Y. Kitamura: ISIJ Int., 2009, vol. 49, pp. 985-91.

39. C. Xuan, H. Shibata, Z. Zhao, P.G. Jönsson, and K. Nakajima: ISIJ Int., 2015, vol. 55, pp. 1642-51.

40. J.F. Paddy: in Surface Tension, Part II, The Measurement of Surface Tension, in Surface and Colloid Science, E. Matijevic, ed., Clarkson College of Technology, Potsdam, NY, 1969, vol. 1, pp. $108-31$

41. F. Bashforth and S.C. Adams: An Attempt to Test the Theories of Capillarity Action, University Press, Cambridge University Press, Cambridge, 1883, pp. 10-50.

42. K. Nakajima: Tetsu-to-Hagané, 1994, vol. 80, pp. 383-8.

43. S. Hara, N. Ikemiya, and K. Ogino: Tetsu-to-Hagané, 1990, vol. 76, pp. 2144-51.

44. K. Nakanishi and J. Szekely: Trans. Iron Steel Inst. Jpn., 1975, vol. 15 , pp. $522-30$

45. L. Zhang, S. Taniguchi, and K. Cai: Metall. Mater. Trans. B, 2000, vol. 31B, pp. 253-66

46. T. Dan, N. Aritomi, K. Ogawa, K. Honma, and T. Kimura: $J$. Jpn. Inst. Met., 1992, vol. 56, pp. 53-9.

Publisher's Note Springer Nature remains neutral with regard to jurisdictional claims in published maps and institutional affiliations. 